\title{
Announcement of the Twenty-fourth Session of the Association of American Anatomists.
}

The twenty-fourth session of the Association of American Anatomists will be held in the Anatomical Laboratory of Johns Hopkins University during the week beginning December 27, 1908, and ending January 2, 1909, in affiliation with the American Association for the Advancement of Science and other Affiliated Scientific Societies. The definite dates for this meeting, details concerning rates, headquarters for the Association, etc., will be given in the preliminary program.

Members of this Association desiring to present papers or give demonstrations should notify the Secretary at a date as early as possible, in any event, not later than December 15th. A prompt reply will enable the Secretary to print and distribute a preliminary program some days before the meeting, and to comply with a request received from $\mathrm{Dr}$. L. O. Howard, to have the program of this Association printed in the general program of all the societies meeting at this time and place. Demonstrations have, for a number of years, formed so prominent a part of the program that their desirability has been well established. It is thought that they might be made more effective if a definite program of demonstrations could be arranged, and a definite hour assigned to each demonstration. This cannot be done unless members will notify the Secretary at an early date of their desire to give a demonstration, giving title, and mentioning space and apparatus needed.

The limited time at the disposal of the Association for the reading of papers and the usual fullness of the program make it desirable that the papers presented be abridged as much as possible. With the ready means now at the disposal of this Association for the publication of papers, it would seem desirable that, so far as possible, the communication be given in the form of full abstracts, the members relying on an early publication for the full papers. Members are urged to bear thib in mind in preparing communications.

It is hoped that a general discussion may be arranged for this meeting. The reading of papers will begin promptly after the first meeting is called to order. The business meeting will be held the second afternoon of the session, otherwise the afternoons are reserved for demonstrations. 
Members are invited to propose for membership in this Association persons eligible thereto. The necessary information regarding eligibility and the manner of proposing members is contained in Article $V$ of the constitution, which reads: "Candidates for membership must be persons engaged in the investigation of anatomical or cognate sciences and shall be proposed in writing to the Executive Committee by two members, who shall accompany the recommendation by a list of the candidate's publications, together with references. The election shall take place in open meeting, a two-thirds vote being necessary." Application blanks may be obtained from the Secretary, and when filled out may be returned to him, who will present the same to the Executive Committee for consideration.

Members with dues in arrears are requested to meet their obligations at an early date. In view of the fact that annual dues of members of this Association include subscription to The American Journal of Anatomy and to The ANatomioal Recond, now published by the Wistar Institute of Anatomy, it becomes eminently desirable that members in arrears pay their dues, in order that the account of this Association with the Wistar Institute, for the present fiscal year, may be closed.

Members are requested to consult the list of members with titles and addresses found in this issue of The ANatomical RECORD to see whether their name, title, and address are correctly given. If not, the Secretary requests that he be communicated with at an early date, and the necessary correction indicated.

G. CaRt Huber, Secretary-Treasurer,

1330 Hill Street, Ann Arbor, Mich. 